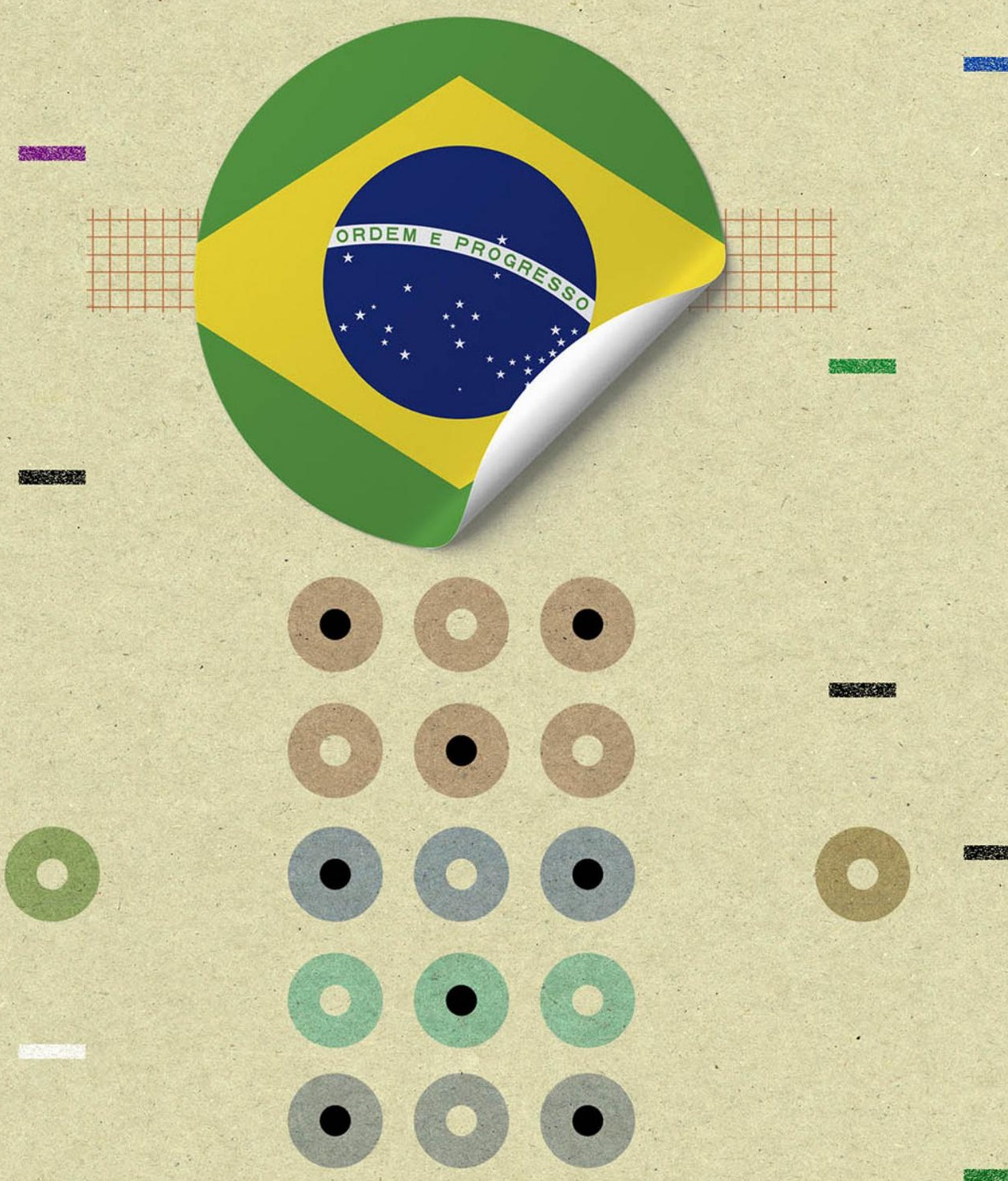

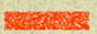

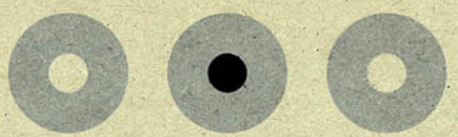

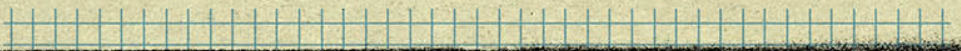

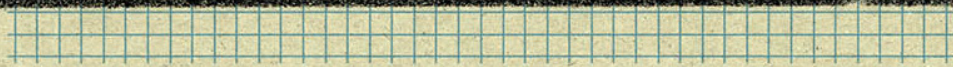

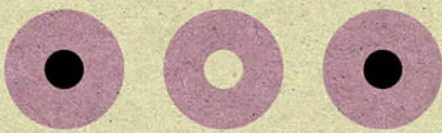




\title{
A policy advocacy como vetor na formação da agenda de políticas: uma análise na janela de oportunidades do processo eleitoral
}

\section{Policy advocacy as a vector in shaping the policy agenda: a analysis of he windows of opportunites of electoral process}

\author{
Renato Antônio de Almeida* | Bruno Tavares** | Suely de Fátima Ramos Silveira*** \\ http://dx.doi.org/10.51861/ded.dmvu.2.007 \\ Recebido em 7 de janeiro de 2021. Aceito em 12 de julho de 2021.
}

\begin{abstract}
Resumo
Esse estudo se propôs a analisar a influência de coalizões de defesa sobre as políticas de assistência social, a partir dos programas de governo dos candidatos à Presidência da República que chegaram ao segundo turno em 2018. A policy advocacy fundamenta a abordagem teórica, caracterizada por princípios e valores em subsistemas de políticas. Como perspectiva de análise, considerou-se o desenvolvimento da cidadania e a representação política na formação das coalizões e na defesa em torno das propostas dos candidatos. Como método, foi utilizada a análise de conteúdo e os resultados apontaram a influência das coalizões dominantes na defesa de políticas e sua relevância na janela de oportunidades proporcionada pelo processo eleitoral. O estudo aponta que as pautas defendidas pelas coalizões dominantes podem elevar determinadas questões ao status de pertencimento da agenda de políticas públicas, mesmo de forma antecipada, diferentemente do que aponta de forma hegemônica a literatura.
\end{abstract}

Palavras-chave: políticas públicas; policy advocacy; assistência social; cidadania; cidadania diferenciada.

\begin{abstract}
This study aimed to analyze the influence of defense coalitions on social assistance policies, based on the government programs of candidates for the Presidency of the Republic that reached the second round in 2018. Policy advocacy underpins the theoretical approach, characterized by principles and values in policy subsystems. As an analysis perspective, the development of citizenship and political representation was considered in the formation of coalitions and in the defense around the candidates' proposals. As a method, content analysis was used and the results showed the influence of dominant coalitions in the defense of policies and their relevance in the window of opportunity provided by the electoral process. The study points out that the agendas defended by the dominant coalitions can raise certain issues to the status of belonging to the public policy agenda, even in advance, differently from what the literature points out in a hegemonic way.
\end{abstract}

Keywords: public policy; policy advocacy; social assistance; citizenship; citizenship differentiated.

\footnotetext{
* Renato Antônio de Almeida

Professor Adjunto, Departamento de Administração, Universidade Federal de Juiz de Fora. Av. Dr. Raimundo Monteiros Rezende, 330, Centro, Governador Valadares - MG, 35010-177.

ORCID: https://orcid.org/0000-0003-2458-113X.E-mail: renato.almeida@ufff.br

** Bruno Tavares

Professor Associado do Departamento de Administração e Contabilidade da Universidade Federal de Viçosa. Av. Peter Henry Rolfs, s/n - Campus Universitário, Viçosa - MG, 36570-900.

ORCID: https://orcid.org/0000-0002-5140-7359.E-mail: btavares@ufv.br

*** Suely de Fátima Ramos Silveira

Professora Associada do Departamento de Administração e Contabilidade da Universidade Federal de Viçosa. Av. Peter Henry Rolfs, s/n - Campus Universitário, Viçosa - MG, 36570-900.

ORCID: https://orcid.org/0000-0002-1303-7190.E-mail: sramos@ufv.br
} 


\section{INTRODUÇÃO}

Ao longo da história, as políticas sociais no Brasil passaram por mudanças profundas, justificadas pelos proponentes e apoiadores de diferentes formas e argumentos, ora privilegiando mais o atendimento de necessidades sociais, ora visando a sustentabilidade econômica do Estado. Essas mudanças ocorreram de forma ampla no sistema de proteção social, alcançando políticas educacionais, de saúde, de habitação e assistência social (ARRETCHE, 1999). Recentemente passaram a vigorar também mudanças profundas no sistema previdenciário, com a PEC 6/2019, de autoria do Executivo Federal, compondo o ciclo das mudanças profundas e em curso do sistema de proteção social, denominado por alguns, dentre eles Esping-Andersen (1995), como sistema de bem-estar social, mais conhecido no Brasil como Sistema de Seguridade Social.

A relevância da participação social deve ser considerada em um cenário de mudanças nas últimas três décadas, dado o contexto democrático existente desde então. Nesse cenário, a influência social e a atuação de grupos de interesse desempenharam seu papel em alguma medida perceptível, seja de forma ativa ou passiva, refletindo demandas sociais e, portanto, contribuindo para a consolidação das políticas do sistema de bem-estar atualmente vigentes. A medida da influência de grupos de interesse, entretanto, considera, dentre outros aspectos, quais são efetivamente as coalizôes influentes e dominantes e os valores interiorizados pelas mesmas, aspectos fundamentais para compreender os mecanismos que definem a formação de coalizôes de defesa mais amplas (SABATIER, 1988; 2011). Portanto, sendo um dos eixos do Sistema de Seguridade, as políticas de assistência social representariam de forma relevante o significado de valores internalizados pela sociedade e o resultado da mobilização social para implementar tais políticas, em direção aos direitos de cidadania (CARVALHO, 2016).

A proteção social, amparada em sua origem pela orientação para a perspectiva de direito do cidadão e dever do Estado brasileiro (SPOSATI, 2013), estabeleceu-se através de um pacto social consolidado na Constituição Federal de 1988 (BRASIL, 1988). A partir dessa perspectiva, propóe-se analisar as políticas de assistência social como resultantes do processo democrático e do exercício da cidadania, objetivando compreender a influência de grupos que se alinham através de seus princípios e valores no sentido de ampliar a visibilidade de determinadas demandas, durante a constituição de coalizóes e propostas no processo eleitoral.

O objetivo desta pesquisa foi analisar de que forma as coalizóes políticas imprimiram nos programas de governo a sua percepção quanto à relevância das políticas de assistência e seus elementos constituintes, supostamente 
representando a relevância do interesse popular, ao longo do pleito para a Presidência da República. Sendo uma forma legítima e representativa de expressão democrática, Weible e Sabatier (2006) argumentam que o processo resultante das coligações políticas permite compreender a aceitação e apoio dos interesses dominantes. Nessa direção, como premissa para esta pesquisa, compreende-se que as propostas dos programas de governo resultam dos acordos emanados das coalizóes dos partidos políticos, as quais deram origem aos programas de governo constituídos.

O processo eleitoral é apontado como uma janela de oportunidades no ciclo de políticas públicas (KINGDON, 1995; SUBIRATS, 2006) a partir da qual uma determinada demanda tem aumentadas as suas chances de sair do âmbito sistêmico, no seio da sociedade, para o âmbito governamental, podendo adquirir o status de problema de política pública inserido na agenda de decisão. As teorias centradas no ciclo de políticas públicas consideram a elevação da agenda ao status de pertencimento dos governos somente a partir da estrutura burocrática formalmente constituída, o que representa um aspecto relevante da análise aqui desenvolvida. Embora as decisões, de fato, ocorram no âmbito burocrático, formal e através de atores com poder para tomada de decisões, acordos e coalizões formadas permeiam todo o âmbito político, antecedendo a legitimação dos decisores no âmbito da burocracia estatal.

Argumenta-se nessa pesquisa que o processo eleitoral, para além de uma janela de oportunidades, participa de forma efetiva do processo de constituição da agenda governamental, oferecendo uma perspectiva distinta da proposta hegemônica do ciclo de políticas públicas. O processo de seleção das questóes relevantes no âmbito público pode ser construído coletivamente, através de um processo bottom up, dada a influência das coalizóes dominantes na constituição das propostas dos candidatos. A teoria da policy advocacy aponta nessa direção, uma vez que o engajamento social, midiático e dos grupos influentes podem proporcionar a elevação de um problema sistêmico à condição de problema governamental (HOWLETT, 2000) e que tais fatores antecedem a constituição formal de um governo.

Portanto, embora a agenda de candidatos e coligaçóes não seja ainda a agenda do governo, propóe-se analisar a influência prévia à sua formação, a partir da argumentação de sua relevância. Essa proposição se orienta pela influência de atores visíveis, embora a mesma seja orientada para a perspectiva do ciclo de políticas públicas (KINGDON, 1995). Alinhados, mas não limitados ao ciclo de políticas públicas, ocorrem movimentos estratégicos no cerne de uma comunidade política, com atores agregados em coalizóes, compostas por pessoas e grupos que compartilham um conjunto de crenças 
normativas e causais, orientados para a defesa de determinadas políticas (SABATIER, 1988; WEIBLE \& SABATIER, 2006).

A análise dos programas de governo resultantes de coalizóes, próximas de um momento decisivo do pleito eleitoral, sendo neste caso o segundo turno das eleiçốes presidenciais, pode contribuir para compreender possíveis tendências na formação de agendas de políticas públicas, ampliando a percepção sobre a relevância das mesmas. Destaca-se então como objetivo deste estudo apreender a influência das coalizóes, através das defesas de políticas na perspectiva dos grupos de interesse dominantes. Ao delimitar a pesquisa no âmbito da Assistência Social, propóe-se avançar também sobre questóes relacionadas aos direitos de indivíduos e grupos mais vulneráveis, que por razôes diversas, se situam à margem dos seus direitos.

A análise proposta será desenvolvida a partir das coalizões políticas em torno dos candidatos à presidência da república em 2018, no pleito eleitoral do segundo turno. Essa escolha se deve à grande possibilidade de cada um dos candidatos ao pleito assumir a presidência, tendo a possibilidade de elevar a um nível maior de importância os compromissos assumidos no plano de governo. Como resultado da pesquisa, espera-se caracterizar as políticas propostas para a assistência social, definidos na Constituição Federal de 1988 (CF-88) e através de categorias a priori fundamentadas na cidadania clássica e diferenciada (MARSHALL, 1967; YOUNG, 1989) e na Policy Advocacy, que fundamenta a estrutura de crenças e valores construídos e internalizados nos sistemas e subsistemas de políticas (SABATIER, 1988).

A ação de grupos de interesse é um processo contínuo, que se manifesta na sociedade em todas as oportunidades, sendo uma delas constituída pela expectativa de que determinado candidato, ao assumir o poder, represente os interesses defendidos por tais grupos. Nessa direção, a questão que orienta essa proposta de pesquisa é compreender a partir de quais aspectos e com que intensidade a assistência social poderia ser percebida como proposta na agenda dos candidatos à presidência da República no segundo turno das eleiçôes de 2018, compreendendo que tais aspectos podem indicar e caracterizar a efetiva influência de grupos de interesse.

Após esta introdução, inicialmente o artigo procura situar a assistência social no contexto brasileiro, a partir de sua evolução e institucionalização, demarcada pela CF-88. Em seguida, apresenta-se a perspectiva teórica da cidadania e sua relação com a participação social baseada nos valores constituídos, permitindo evoluir, no tópico seguinte, para o papel da policy advocacy no contexto político e social, considerando os aspectos da representação política, bem como suas limitaçóes e das coalizóes de defesa. A seguir é apresentada a abordagem metodológica, centrada na análise de conteúdo 
dos programas de governo, passando em seguida para a análise, discussão dos resultados e consideraçóes finais.

\section{ASSISTÊNCIA SOCIAL NO CONTEXTO BRASILEIRO}

Nas últimas três décadas, desenvolveu-se no Brasil um novo cenário sociopolítico, que teve como marco a CF-88 (BRASIL, 1988). No capítulo II, que trata da seguridade social, a carta magna estabelece os princípios da assistência social, destacando como objetivos a proteção à família, às crianças e adolescentes, à empregabilidade, às pessoas portadoras de deficiência e ao idoso, com recursos específicos da seguridade social, previstos na própria Constituição. O novo pacto social que se estabeleceu, por ser originado no seio da sociedade através de um processo democrático, representa em boa medida a forma como essa sociedade entende as políticas sociais, assim como compreende a relevância da assistência social e o seu papel na proteção aos cidadãos em situação de vulnerabilidade.

Sendo parte de um contexto maior que se estabelece com o sistema de seguridade social, a assistência social é resultante de um processo amplo e histórico, que se desenvolveu a partir da evolução humana em um contexto essencialmente capitalista. Não seria, portanto, um fenômeno resultante da criatividade ou do populismo político, mas sim resultante de vários fatores, dentre eles a democracia e a luta de classes, em um cenário de profundas desigualdades sociais (KERSTENETZKY, 2014; SPOSATI et al., 1998).

Esse processo culminou no estágio de desenvolvimento social que se convencionou denominar de Estado de bem estar social, que teve seu ápice no período posterior à segunda guerra mundial até na década de 1980, quando se iniciou seu período de estabilização e aparente amadurecimento. Nessa mesma época, desenvolvia-se de forma célere e pujante em países mais desenvolvidos o welfare state, que incluía de forma substancial, dentre outros, os serviços sociais públicos, tendo como uma das principais molas propulsoras a mobilização popular, notadamente da classe trabalhadora e de grupos socialistas Kerstenetzky (2014).

O que pode ser concebido como um período áureo da seguridade social no Brasil iniciou-se simultaneamente com o amadurecimento do welfare state em países pioneiros nesse sentido (ESPING-ANDERSEN, 1995), embora em ritmo e alcances sociais bem diferentes. Assim, quando mudanças nas políticas de assistência ocorriam em países mais desenvolvidos, em estágio de relativa maturidade, acompanhadas de discursos políticos de austeridade, instituía-se no Brasil a CF-88, um fato novo e relevante, que significou um importante marco para a consolidação da seguridade social. Por- 
tanto, embora o desenvolvimento da assistência social no Brasil possa de fato ter algum teor de influência externa, as evidências apontam para uma construção histórica essencialmente desenvolvida no seio da sociedade brasileira.

A história do desenvolvimento da assistência social no Brasil desvela um processo caracterizado por avanços e retrocessos sociais, econômicos e democráticos. Esse longo percurso é apontado em um primeiro momento no Brasil pelo processo de colonização, seguido de um período de adaptação à sua condição de independência e a definição de uma estrutura própria, em um longo e sofrível processo de desenvolvimento, buscando alcançar uma estrutura aceitável política e socialmente, em direção a uma democracia ainda em desenvolvimento. Esses aspectos são apontados por Carvalho (2016), que relata a partir dos mesmos um processo de evolução da cidadania, potencializada por grupos de interesses diversos e partidos políticos dominantes, seja a partir de argumentos sociais ou liberais.

Há amplos argumentos que corroboram com a perspectiva de influência dos grupos de interesse na constituição dos sistemas de bem-estar social (ESPING-ANDERSEN, 1995; KERSTENETZKY, 2014), embora alguns autores questionem o poder de tal influência devido às limitaçóes sociais e de representatividade. No que tange à pouca representatividade na defesa de políticas sociais, são colocadas em evidência as classes sociais empobrecidas e marginalizadas, com cidadãos relegados a uma condição de categoria inferior e que, portanto, não exerceriam de forma mínima seus direitos de cidadania. Como agravante, resta a naturalização histórica desta condição pela sociedade.

Desta forma, a representatividade não parece alcançar a amplitude necessária para cumprir o seu papel, perenizando classes subalternas e de pouca expressão política e social, dependentes da eventual benevolência do próprio Estado que as aprisiona (YAZBEK, 2016), sem conseguir alcançar objetivos sustentáveis de políticas de assistência social que proporcionem a dignidade humana, permitindo-lhes exercer satisfatoriamente seus direitos de cidadania. Nesse contexto, emergem questóes que se originam com a clara percepção de um quadro ainda em construção, com evidentes e frequentes retrocessos das políticas públicas de assistência social no Brasil, ao vislumbrar os aspectos de inconsistência, descontinuidade, pouca efetividade e da prática recorrente do assistencialismo.

Ao verificar o cenário relativamente recente, constata-se que o Brasil desponta como destaque em relação à desigualdade (OCDE, 2018), agravados por indicadores atuais que apontam para o aumento da violência doméstica e contra crianças, adolescentes e idosos; os portadores de necessidades especiais sofrem com o descaso, o desemprego amplia-se em escala alarmante, 
dando origem a um exército de desalentados (IPEA, 2019). O nível de emprego é uma variável determinante em um cenário de desigualdades, principalmente quando não existem políticas públicas que assistam pessoas que perderam sua renda por um período prolongado. Esse aspecto é apontado por Esping-Andersen (1995) como um fator relevante em suas discussóes sobre o sistema de bem-estar social e também por Kerstenetzky (2014) ao discutir a perspectiva do investimento social. Nesse cenário, as forças que se estabelecem no âmbito da esfera pública atuam com influências múltiplas, podendo resultar na manutenção, no ajuste e/ou na estruturação de novas políticas públicas.

Não obstante os aspectos que apontam para uma efetividade questionável da assistência social, as políticas estabelecidas indicam uma direção apontada pela sociedade, uma vez que estas significam a consolidação de um processo cultural, político e de influência, sob a ótica da policy advocacy framework (JENKINS-SMITH et al., 2014; SABATIER, 1988; 2011; WEIBLE \& SABATIER, 2006). A partir desta construção teórica, argumenta-se de forma propositiva que o percurso da assistência social brasileira foi orientado por um conjunto de valores construídos socialmente, através de um processo de aprendizado, sedimentando crenças e valores relevantes para a proposição das políticas públicas vigentes. Tais aspectos constituíram os direitos e práticas de cidadania atuais, com seu curso ininterrupto e com práticas democráticas ainda em construção.

\section{CIDADANIA CLÁSSICA, DIFERENCIADA E PARTICIPAÇÃO COLETIVA}

Considerando que a construção coletiva de cidadania reflete os valores sociais, o senso de cidadania é apreendido não somente com o sentimento consciente de pertencimento a uma comunidade nacional. Para além da cidadania formal, valores compartilhados orientam o verdadeiro sentido de participar de uma sociedade que compreende e pratica a igualdade de direitos e deveres (CARVALHO, 2016). Ao conceituar a cidadania, Marshall (1967) destacou a participação como aspecto fundamental, no sentido de indagar quem participaria das decisões e como seria essa participação.

Os direitos de cidadania representam a construção de valores como elementos influentes no âmbito social e político e, portanto, sendo fundamentalmente norteadores na proposição de políticas sociais. A representatividade e a influência de indivíduos e de grupos de interesse contribuem para elevar o nível de percepção da importância sobre políticas públicas (SUBIRATS, 2006) e esse processo pode ser compreendido na perspectiva da policy 
advocacy (JENKINS-SMITH et al., 2014; SABATIER, 1988, 2011; WEIBLE \& SABATIER, 2006).

A forma de condução das políticas públicas de assistência social ao longo do tempo proporciona uma perspectiva que permite apontar alguns aspectos relevantes em relação à construção da cidadania coletiva. Assim pode-se perceber como possibilidade, a partir do exercício da cidadania, exercer o direito de liberdade de expressão, apoiando ou contestando ações do Estado, mesmo sob determinado nível de repressão. Esse argumento vai na direção do comportamento coletivo, através do modelo proposto por Granovetter (1978), dentre outros e exemplificado por (CARVALHO, 2016), ao relatar eventos ocorridos ao longo da história nas últimas décadas do Brasil, como o movimento das Diretas Já na década de 1980 e os protestos pró-impeachment do então Presidente Fernando Collor na década de 1990.

Ainda segundo Carvalho (CARVALHO, 2016), ao longo do tempo é possível verificar um descontentamento coletivo muitas vezes não verbalizado, mas que se manifesta em determinado momento, demonstrando o posicionamento de grupos de interesse e o surgimento de novos atores políticos, influenciando na formulação de novas agendas. É preciso, porém, considerar que a prática da cidadania é construída a partir de um processo longo, subjetivo e complexo, definido a partir de diversos aspectos da cidadania formal e substantiva.

A concepção de Marshall (1967) para o desenvolvimento da cidadania passa, necessariamente, por aspectos históricos. Assim, o autor define os elementos civis, políticos e sociais para explicar como a mesma se constitui. O elemento civil compóe-se da liberdade individual, que compreende os direitos básicos de expressão, de pensamento, de propriedade e de justiça. $\mathrm{O}$ elemento político pode ser compreendido como o direito à participação institucional, como membro ou como eleitor, podendo exercer sua influência sobre o governo. Por fim, como direitos sociais compreende-se o direito ao mínimo bem-estar até a participação nas riquezas produzidas pela sociedade e de uma existência digna.

A expressão mais completa de cidadania, segundo Marshall (1967), requer um Estado social democrático liberal, com garantia de direitos civis, políticos e sociais para todos. Dessa forma, seria garantida aos membros da sociedade uma participação plena. Caso um ou mais direitos fossem retirados ou violados, o direito à cidadania estaria prejudicado, culminando em processos de marginalização e exclusão social.

A cidadania formal ou legal, segundo Kymlicka e Norman (1994), se diferencia da cidadania como prática, pois é preciso considerar a participação do indivíduo em uma comunidade, exercendo seu direito e dever de contribuir e de influenciar os aspectos da vida social, política e prática da coletividade. 
Portanto, uma teoria adequada para a cidadania envolve uma ênfase nas responsabilidades e virtudes. Assim, propóe-se avançar um pouco mais na teoria e expandir o conceito de cidadania, compreendendo a necessidade de adaptações em função do crescente pluralismo social e cultural das sociedades modernas (KYMLICKA \& NORMAN, 1994).

A partir dos aspectos constituintes da cidadania, é relevante compreender que "Cidadania não é apenas um status, definido por um conjunto de responsabilidades. É também uma identidade, uma expressão da sua participação em uma comunidade política" (KYMLICKA \& NORMAN, 1994, p. 369). Desta forma, destaca-se que o conceito clássico de cidadania não seria suficiente para acomodar grupos excluídos ou "diferenciados", que se evidenciam e reivindicam cada vez mais seus direitos nas modernas sociedades.

A existência, de fato, de grupos diferenciados e excluídos demanda uma inserção cidadã também diferenciada. Tal inclusão se daria a partir de indivíduos unidos por interesses comuns, como por exemplo: raça, nacionalidade, condiçẫo socioeconômica, gênero e outras. Essas demandas representariam um avanço para além da cidadania clássica, denominada "cidadania diferenciada” (YOUNG, 1989, p. 258), diferindo conceitualmente da concepção de uma cidadania universal. Assim, a expressão da cidadania em direção a uma plenitude não pode mais ser compreendida somente através de suas dimensões clássicas, uma vez que seu conceito adquiriu uma dimensão socialmente mais complexa e inclusiva.

Embora remeta à noção ortodoxa de cidadania o fato de tratar pessoas como indivíduos com iguais direitos perante a lei, tanto Young (1989) quanto Kymlicka e Norman (1994) não contestam os pressupostos de Marshall (1967), mas propõem avanços em suas proposições teóricas. Considerando as diversas perspectivas, compreende-se que a sociedade moderna tende a se organizar também com base em direitos diferenciados, contribuindo para evolução do conceito clássico de cidadania. Esse aspecto implica em uma nova perspectiva de valores e, consequentemente, na formação de novos grupos de interesse e de novas e mais influentes coalizóes de defesa.

Considerando as proposições teóricas aqui abordadas (KYMLICKA \& NORMAN, 1994; MARSHALL, 1967; YOUNG, 1989), uma concepção mais inclusiva de cidadania permite compreender melhor a existência das classes subalternas (SPOSATI et al., 1998; YAZBEK, 2016), indo na direção do que Heiwood (2004) denomina cidadãos de segunda classe. Desta forma, é possível perceber também de forma mais ampliada o aspecto da exclusão, que não se trata somente de uma perspectiva socioeconômica, mas também de participação. Emerge então o problema da sub-representação, frequentemente existente na formação de coalizóes de defesa de políticas. 
Assim, é possível compreender também cenários nos quais podem surgir coalizões construídas e sustentadas por uma minoria dominante, que de forma sistemática, efetiva e muitas vezes legítima (através de eleiçôes, partidos políticos e grupos de interesse) definem os rumos da participação "democrática". É frequente não fazerem parte desta representação, portanto, muitos dos grupos excluídos, que não conseguem se fazer representar por diversas razóes. Segundo Heiwood (2004), tal cenário é possível quando grupos diferenciados ou cidadãos de segunda classe têm sua participação limitada por desvantagens, sejam elas sociais, econômicas, políticas ou de quaisquer naturezas.

\section{O PAPEL DA POLICY ADVOCACY NO CONTEXTO POLÍTICO E SOCIAL}

A construção da cidadania é um processo com componentes históricos e muitas vezes não estruturado, constituído por um conjunto de aspectos legais, sociais, políticos, econômicos e culturais, dentre outros. Essa é a perspectiva da constituição dos direitos de cidadania em uma condição do Estado democrático, no qual compreende-se que os direitos constituídos e a participação social são elementos indissociáveis, tornando-se um patrimônio de toda a sociedade. Tais aspectos são elementos que podem ser traduzidos em larga medida pela cultura socialmente construída (DAGNINO, FERLIM \& ROMANELLI, 1998).

Nesse sentido, a representação social e política são elementos constituintes da esfera pública, não obstante suas limitaçóes. Por esta razão, é possível inferir que a representação da sociedade reflete, em larga medida, a consciência coletiva e as demandas sociais, representando a cultura coletiva, que reflete os valores constituintes da cidadania, de forma ampla. Essa perspectiva encontra suporte também na teoria da formação de agenda através da policy advocacy, que aponta o engajamento e a influência da opinião pública e da mídia como elemento constituinte das agendas políticas e do governo, ao evidenciar e tornar relevante um determinado problema ou proposta de intervenção (SECCHI, 2012). É uma assertiva que destaca a influência dos mais diversos segmentos da sociedade a partir dos valores predominantes, na priorização das demandas públicas.

Os conceitos de cidadania (MARSHALL, 1967) e cidadania diferenciada (KYMLICKA \& NORMAN, 1994; YOUNG, 1989) no contexto democrático e político não são uma imposição social. Portanto, compreende-se que os programas de governo são resultado da construção de um projeto político, que demandou acordos e coalizóes. Sendo submetido a influências diversas, são acordos e propostas que definem as bases para políticas e arranjos pos- 
teriores, que incluem ideologia de partidos políticos e demandas oriundas de grupos de interesse provenientes de diversas influências sociais. Dentre as teorias explicativas de formação de políticas públicas, a policy advocacy apresenta argumentos explicativos com uma fundamentação robusta, que reforçam a influência dos grupos de interesse em um instante anterior à formação de agenda. É um processo que ocorre através da participação efetiva e, portanto, decisória, na constituição do quadro político.

A fundamentação teórica das coalizões de defesa oferece uma perspectiva ampla para compreender o processo através do qual ocorre a influência popular, passando pela construção dos programas dos candidatos e por sua influência no processo eleitoral. Ao descrever sua concepção de advocacy, Sabatier (1988) descreve como compreende tal influência, que pode se estabelecer em vários cenários e em vários momentos de um processo político. Uma proposição introdutória e simples para a advocacy é o significado de influência, de pleitear uma causa, fazer lobby, apoiar ou recomendar uma determinada ação ou posicionamento.

O conceito de advocacy, segundo Jenkins (1987), pode ser compreendido também como lobby, utilizado para abordar legisladores ou outros decisores, com o objetivo de influenciar os mesmos. Um significado mais diverso de advocacy, segundo Jenkins (1987) pode ser compreendido também como uma instrumento para defesa de direitos, que inclui instituiçóes legais e açóes no sentido de participar e monitorar programas de governo, inclusive contribuindo para a definição de regras e procedimentos.

\section{METODOLOGIA}

O método de análise foi desenvolvido para analisar e identificar possíveis relaçôes entre a construção dos programas de governo e a influência exercida pela respectiva representação política, na perspectiva da policy advocacy e dos valores relacionados à cidadania, a partir das proposiçôes teóricas apresentadas. O campo de análise delimitou-se pelas propostas de políticas relacionadas à assistência social, desconsiderando os demais aspectos existentes nos respectivos programas. O método usado foi a análise de conteúdo desenvolvido por Lasswell (BARDIN, 1977).

Os documentos analisados foram obtidos no acervo disponibilizado no site do Tribunal Superior Eleitoral (TSE). A escolha dos programas de governo dos candidatos do segundo turno justifica-se por pertencerem a coalizóes dominantes e, portanto, significativamente representativas para a perspectiva de análise proposta. Ao definir como objeto de análise os programas de governo do último pleito eleitoral (2018) levou-se em considera- 
ção o objetivo de compreender a concepção do significado da cidadania e da representação dos interesses mais próximos do momento atual, procurando apreender a cultura e os valores coletivos em dado momento histórico, em um cenário onde não havia candidatos pleiteando uma reeleição.

A apuração dos votos do primeiro turno foi concluída na noite de 08/10/2018, apontando os candidatos mais votados e que concorreram à eleição para a Presidência da República no segundo turno de 2018. O maior número de votos foi para a coligação PSL-PRTB, com 49.276.990 dos votos (46,03\%), seguido da coligação PT-PCdoB-PROS, que obteve 31.342.005 dos votos $(29,28 \%)$. Desta forma definiu-se as coligaçóes que participaram do pleito do segundo turno das eleiçốes presidenciais de 2018.

Foi realizada inicialmente uma leitura flutuante do material, com o objetivo de ter um contato inicial com o mesmo. O processo de pré-análise é recomendado por Bardin (1977) como uma das etapas para organização e seleção, sendo útil também para a formulação das primeiras ideias. Nessa etapa o propósito é ter uma primeira impressão e iniciar uma análise superficial da relação entre os textos e as categorias de análise, definidas no referencial teórico. Após leituras mais atentas, foi possível identificar melhor a estrutura dos documentos e definir os elementos centrais, bem como os aspectos mais relevantes das propostas, de uma forma mais ampla.

Para caracterizar as categorias de análise, foram utilizadas como referência a CF-88, os conceitos de cidadania clássica (MARSHALL, 1967) e cidadania diferenciada (YOUNG, 1989). Tais categorias se referem, respectivamente, aos objetivos, público e serviços de assistência social e aos aspectos constituintes da cidadania. Assim, a escolha do processo de análise baseou-se nos aspectos explícitos dos textos, a partir de palavras e frases contextualizadas pelas categorias definidas, tendo como suporte o software ATLAS.ti.

A seguir é apresentada a síntese da análise (Quadro 1), relacionando as categorias ao número de vezes em que as citaçóes foram identificadas e sua associação com as categorias. A primeira e a segunda coluna identificam as categorias, a partir das teorias apresentadas. Na quarta coluna são contabilizadas as citaçôes encontradas nos programas de governo que se relacionam com cada uma das categorias, subdivididas pela quantidade unitária das citaçóes e pelo percentual relativo em relação ao total de citaçóes de cada categoria. 
Quadro 1 - Análise de conteúdo a partir das categorias de assistência social e cidadania nos programas das coligações PSL-PRTB e PT-PCdoB-PROS.

\begin{tabular}{|r|l|l|r|r|r|r|}
\hline Item & \multicolumn{1}{|c|}{ Categoria } & \multicolumn{1}{c|}{ Referências } & \multicolumn{2}{c|}{$\begin{array}{c}\text { Citações } \\
\text { PSL-PRTB } \\
\text { (unid. / \%) }\end{array}$} & \multicolumn{2}{c|}{$\begin{array}{c}\text { Citações } \\
\text { PT-PCdoB-PROS } \\
\text { (unid. /\%) }\end{array}$} \\
\hline 1 & Família & $\begin{array}{l}\text { CF-88 Título VIII, Cap. II, } \\
\text { Seção IV, Art. 203 }\end{array}$ & 2 & 18,18 & 9 & 81,82 \\
\hline 2 & Maternidade & Idem anterior & 0 & 0,00 & 3 & 100,00 \\
\hline 3 & Infância & Idem anterior & 1 & 5,88 & 16 & 94,12 \\
\hline 4 & Adolescência & Idem anterior & 2 & 9,52 & 19 & 90,48 \\
\hline 5 & Idosos & Idem anterior & 1 & 25,00 & 3 & 75,00 \\
\hline 6 & Trabalhadores & Idem anterior & 2 & 9,52 & 19 & 90,48 \\
\hline 7 & Pessoas com deficiência & Idem anterior & 0 & 0,00 & 4 & 100,00 \\
\hline 8 & Cidadania civil & Marshall (1967) & 9 & 42,86 & 12 & 57,14 \\
\hline 9 & Cidadania política & Marshall (1967) & 2 & 33,33 & 4 & 66,67 \\
\hline 10 & Cidadania social & Marshall (1967) & 3 & 6,52 & 43 & 93,48 \\
\hline 11 & Cidadania diferenciada & Young (1989) & 0 & 0,00 & 22 & 100,00 \\
\hline Total & & & 2 & 13,07 & 154 & $\mathbf{8 6 , 9 3}$ \\
\hline
\end{tabular}

Fonte: Elaboração própria.

\section{ANÁLISE E DISCUSSÃO DOS RESULTADOS}

\section{Análise do programa de governo da coligação PSL-PRTB}

Constata-se na apresentação do programa sua intenção explícita de atender os aspectos legais, solidários e critérios de eficiência, o que pode ser traduzido pelos tópicos iniciais "Constitucional, eficiente e fraterno". Em seguida surge ainda na apresentação a associação direta entre "cidadania e liberdade". São destacados valores como "família" e "propriedade privada" e verifica-se a repetição em diversos pontos das palavras "fraternidade, solidariedade e compaixão”, sempre associadas a valores a serem conquistados. Em alguns pontos os termos "cidadão e cidadania, direitos, liberdade" e ideais de patriotismo são destacados. Há um apelo presente de forma chamativa, de um ideal libertário, explicitando que todos estão sujeitos a algum tipo de aprisionamento. A seguir encontra-se a nuvem de palavras ilustrando seu destaque relativo no texto analisado (Figura 1 ).

O programa destaca como prioridades "segurança, saúde e educação", sem uma vinculação direta com os princípios mínimos, definidores do bem-estar social, representados pelo sistema de seguridade, que são a previdência, assistência e saúde. Há uma ênfase em direção à segurança e o combate à corrupção. O liberalismo é apresentado como a solução para diversos problemas, como corrupção e subdesenvolvimento econômico. 
Figura 1 - Termos em destaque no programa da coligação PSL-PRTB

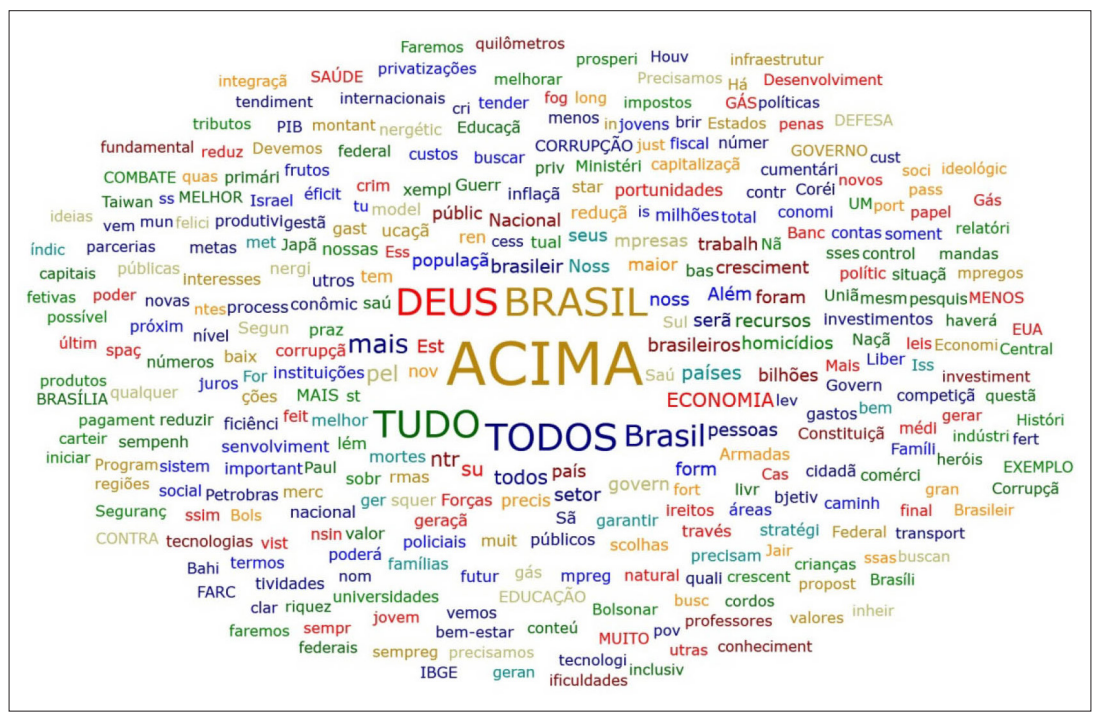

Fonte: elaboração própria, com suporte do ATLAS.ti.

O termo "assistência”, quando surge, é de forma pontual e nesses momentos está associado ao contexto de socialismo, controle e economia. O termo "assistência social" é mencionado duas vezes, sendo uma no contexto econômico, tratando da "bolsa família" e outra com um posicionamento crítico a ações de assistência, ao mencionar o "bolsa crack".

A CF-88 (BRASIL, 1988) orienta sobre o público a ser atendido pelas políticas de assistência social e os serviços que devem ser ofertados. Em relação ao público que se propõe a atender, o programa da coligação PSL-PRTB não menciona maternidade e o serviço de habilitação e reabilitação. Destaca-se como público a ser atendido, em ordem decrescente, os idosos, as famílias, os adolescentes e por último, as crianças. Como propostas de serviços, há referências ao estabelecimento de uma renda mínima mensal e geração de trabalho, seja através do emprego ou empreendedorismo.

Destaca-se que determinados públicos e serviços, a partir de uma análise contextual, apresentam de forma superficial e periférica. A título de exemplo, podem ser apontadas ações pontuais, como o programa de prevenção de saúde bucal para gestantes e educação física no programa de saúde da família.

Os idosos são citados como merecedores de atenção fraterna, mas não são incluídos como público alvo das políticas propostas. Não são apresentadas ações específicas em relação à proteção e cuidados com crianças e adoles- 
centes, os quais são mencionados nas discussões sobre violência e educação. Algumas açốes são mais específicas, como, por exemplo, a modernização do programa bolsa família.

Uma análise das categorias constituintes da cidadania, apresentados por Marshall (1967) e Young (1989), comparativamente às categorias identificados no programa de governo da coligação PSL-PRTB indicam um maior destaque à cidadania civil, a partir de citaçóes de liberdade, direito à propriedade e liberdade de imprensa. As categorias cidadania política e cidadania social surgem através de citaçóes dispersas, denotando irrelevância na perspectiva da proposta apresentada.

Não foram encontradas citaçóes que remetam à cidadania diferenciada (YOUNG, 1989). Indivíduos que pertençam a grupos susceptíveis a vulnerabilidades sociais (crianças e adolescentes, idosos, mulheres em situação de violência, portadores de necessidades especiais), de acordo com a CF-88 (BRASIL, 1988) também não encontram eco nas propostas do referido programa. Embora seja citada de forma pontual a fraternidade, não há propostas concretas nesse sentido.

São escassas as mençôes à cidadania social. Não há propostas em relação à cidadania diferenciada, que se orienta para os aspectos de inclusão de indivíduos, grupos e classes sociais. De uma forma mais ampla, as citações do programa da coligação PSL-PRTB remetem a um conjunto de critérios que correspondem a um total de 13,07\% do total de propostas apresentadas em ambos os programas, relacionadas à assistência e cidadania.

\section{Análise do programa de governo da coligação PT-PCdoB-PROS}

O programa destaca como prioridades o que denomina de redemocratização, com um apelo à soberania nacional e popular. Os pontos focais do programa são o desenvolvimento social e econômico, com uma atenção maior aos aspectos do direito, geração de emprego e inclusão social, destacando a diversidade existente. As necessidades mais emergentes são apontadas como combate à crise e geração de emprego, através de investimento público, retomada de obras paralisadas, reativação da produção e consumo e estímulo ao empreendedorismo. O discurso predominante é pela manutenção do domínio estatal e do fortalecimento de setores estratégicos, como o petróleo e indústrias.

Verifica-se no escopo geral do programa em questão um amplo conjunto de propostas que remetem à assistência social e à cidadania. A "assistência” é mencionada diversas vezes, predominantemente associada à saúde, educação ou social. A palavra "social” é citada dezenas vezes, sendo utilizada de forma ampla em toda a extensão do programa, sempre associada à assistência, educação, saúde, esportes, integração, desenvolvimento, controle, inclusão, 
sustentabilidade, bem-estar e justiça, dentre outras. A assistência social é mencionada objetivamente em várias oportunidades em programas específicos, como habitação, luz para todos, gás a preço justo, qualificação profissional, urbanização, alimentação e agricultura, dentre outros. Abaixo (Figura 2) está representado o conjunto de citaçóes destacadas por sua relevância relativa no texto.

Figura 2 - Termos em destaque no programa da coligação PT-PCdoB-PROS

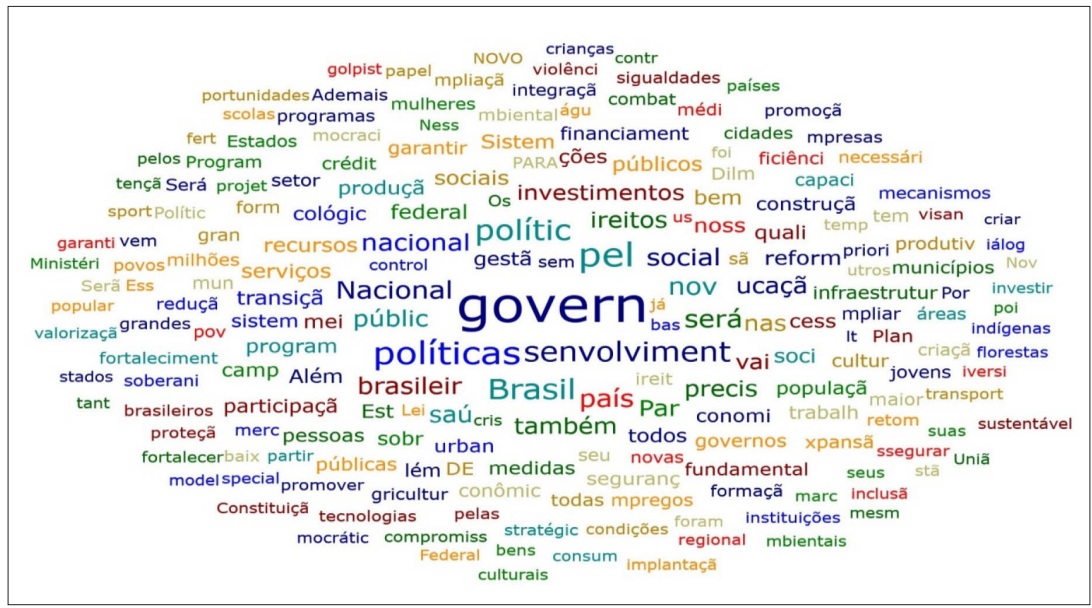

Fonte: elaboração própria, com suporte do ATLAS.ti.

Comparativamente à CF-88 (BRASIL, 1988), o programa da coligação PT-PCdoB-PROS menciona de forma abrangente e contextual a assistência a jovens e adolescentes, à infância e à família. De forma mais limitada são citados a família, a maternidade e os idosos. De forma geral, todo o público referenciado pela CF-88 foi citado como beneficiário das propostas de assistência. Os idosos e a maternidade receberam menor atenção proporcionalmente, se comparados aos demais públicos. As mençôes à família, jovens e crianças estão amplamente associadas a diversas ações objetivas e propostas de políticas específicas, seja para proteção, garantia de renda mínima, saúde, educação ou outras.

Os serviços de assistência social, conforme orientação da CF-88 (BRASIL, 1988) foram identificados de forma ampla em seus aspectos principais no texto. Destacam-se no programa as propostas relacionadas à assistência à geração de emprego, integração ao trabalho e empreendedorismo, tanto para 
pessoas em situação de vulnerabilidade econômica, devido ao desemprego, como pessoas com vulnerabilidade econômica devido à impossibilidade física de trabalho. Nesses aspectos, há uma forte associação com a cidadania clássica (MARSHALL, 1967) e diferenciada (YOUNG, 1989), a lembrar elementos essenciais como direito, dignidade, participação, inclusão, proteção, educação e renda. Evidenciam-se no referido programa os aspectos nos quais se assentam os princípios amplos da assistência social e cidadania.

Partindo das categorias específicas da cidadania, a coligação PT-PCdoB-PROS apresenta uma identificação dos elementos da proposta do programa alicerçados na ótica da cidadania formal, substantiva e diferenciada. Verifica-se que os direitos individuais são lembrados de forma ampla, bem como os direitos políticos, que incluem a participação na formação de políticas públicas. Os direitos à assistência social são citados de forma vinculada à estrutura da seguridade, mencionando os pilares da saúde, da previdência e assistência social, inclusive em associação com políticas transversais, como educação. Portanto, constata-se ao mesmo tempo uma vinculação entre as políticas de assistência com políticas de educação. Verifica-se também que os direitos plenos à inclusão, relacionados à cidadania diferenciada, estão amplamente contemplados pelo programa, ao serem associados à economia, sociedade, emprego e outros aspectos que atualmente apontam para vulnerabilidades sociais. O programa de governo do PT-PCdoB-PROS apresenta $86,93 \%$ do total de citações que podem ser associadas às categorias de assistência social e cidadania, ao analisar o conjunto de citaçóes dos dois programas de governo.

\section{CONSIDERAÇÕES FINAIS}

Em um cenário de democracia, prevalecem as coalizóes no sentido de consolidar determinada posição para acesso ao poder, mesmo considerando as mazelas de uma representatividade limitada. Tais coalizóes se constituem a partir de representaçóes políticas, que conduzem a um status de maior relevância determinados interesses. A teoria da policy advocacy aponta que em um processo de consolidação das coalizões de defesa, as políticas públicas têm sua formatação influenciada por um sistema de crenças e valores que são uma construção, baseada em crenças mais profundas e superficiais, definidas pela sociedade, incorporados e aprimorados ao longo do tempo, através de um processo de aprendizado (SABATIER, 1998). Esse estudo identificou, a partir da abordagem teórica e de uma análise de dados secundários, uma relação de influência das coalizões de defesa de políticas à efetiva prática da cidadania (KYMLICKA \& NORMAN, 1994). 
Considerando a representação política dominante e sua influência no que tange às crenças e valores, a análise dos programas de governo externou de forma ampla, diferenças profundas entre ambos, o que se explica a partir de coalizóes com fundamentos políticos e sociais não convergentes. A análise desenvolvida identificou especificamente aspectos relacionados à assistência social e cidadania, revelando dois programas de governo com propostas muito divergentes, considerando a defesa de direitos relacionados à cidadania e à assistência social. No primeiro programa de governo da coligação PSL-PRTB, identificou-se uma defesa mesmo que limitada em relação à cidadania civil, contrastando com uma defesa inexpressiva das demais categorias de cidadania, juntamente com propostas pouco expressivas de assistência social. No programa de governo da coligação PT-PCdoB-PROS foi possível identificar uma defesa ampla da cidadania, indo em direção às proposições de Marshall (1967) e Young (1989), ao mesmo tempo em que se constatou uma defesa relativamente consistente e ampla de propostas para assistência social.

Atendendo à proposta de pesquisa, foi possível identificar as categorias que definem os elementos da cidadania nos programas de governo analisadas, bem como estabelecer uma relação entre as mesmas e as respectivas coalizóes de defesa. A consistência e intensidade das propostas nos respectivos programas indicou um conjunto de valores não apenas divergentes, mas característicos de cada coalizão. Foi possível constatar que há, nos casos analisados, uma associação entre os valores caracterizadores da cidadania clássica e diferenciada e as propostas de assistência social, o que é indicado não apenas pela frequência e natureza das propostas, mas também pela sua coerência e contexto, considerando inclusive as ações propostas para sua efetivação.

Os resultados apontaram propostas formalmente estabelecidas por coalizốes políticas, as quais podem ser compreendidas, individualmente, como uma ampla coalizão de defesa. Os resultados evidenciaram um conjunto de características de cada coalizão, as quais permitem identificar não apenas os interesses, mas também o resultado de propostas construídas e interiorizados ao longo do tempo. Trata-se de um conjunto de aspectos que caracterizam cada uma das coalizốes, com subsistemas de crenças mais profundas que serão preponderantes em relação às demais.

No sentido proposto pelo objetivo geral dessa pesquisa, verificou-se que as propostas são definidas no âmbito de um contexto político, cujos representantes conseguem imprimir no âmbito de uma determinada coalizão os interesses dominantes. Desta forma, são estabelecidos os princípios e diretrizes que constituirão a base para a legitimação das políticas públicas que poderão futuramente adquirir relevância na agenda do candidato eleito. As propostas podem ser compreendidas também como resultantes da cultura e 
dos valores assimilados de forma coletiva pelos respectivos grupos de coalizão, considerando as eventuais limitações de representação política e social. Os resultados da pesquisa corroboram com a perspectiva de análise proposta, considerando a teoria da policy advocay como uma alternativa às teorias do ciclo político no que se referem à formação da agenda de políticas.

A pesquisa não objetivou caracterizar os subsistemas de cada uma das coalizões, o que pode ser compreendido como uma proposta para pesquisas futuras. Tal análise permitiria caracterizar as crenças mais profundas e mais superficiais, identificando os subsistemas existentes e também o conjunto de valores interiorizados. Essa pesquisa pode somar-se também a outras que se proponham a tornar-se um ponto de partida para estudos posteriores, que se proponham a desenvolver uma análise longitudinal das propostas de políticas públicas apresentadas pela coalizão vencedora no pleito eleitoral analisado.

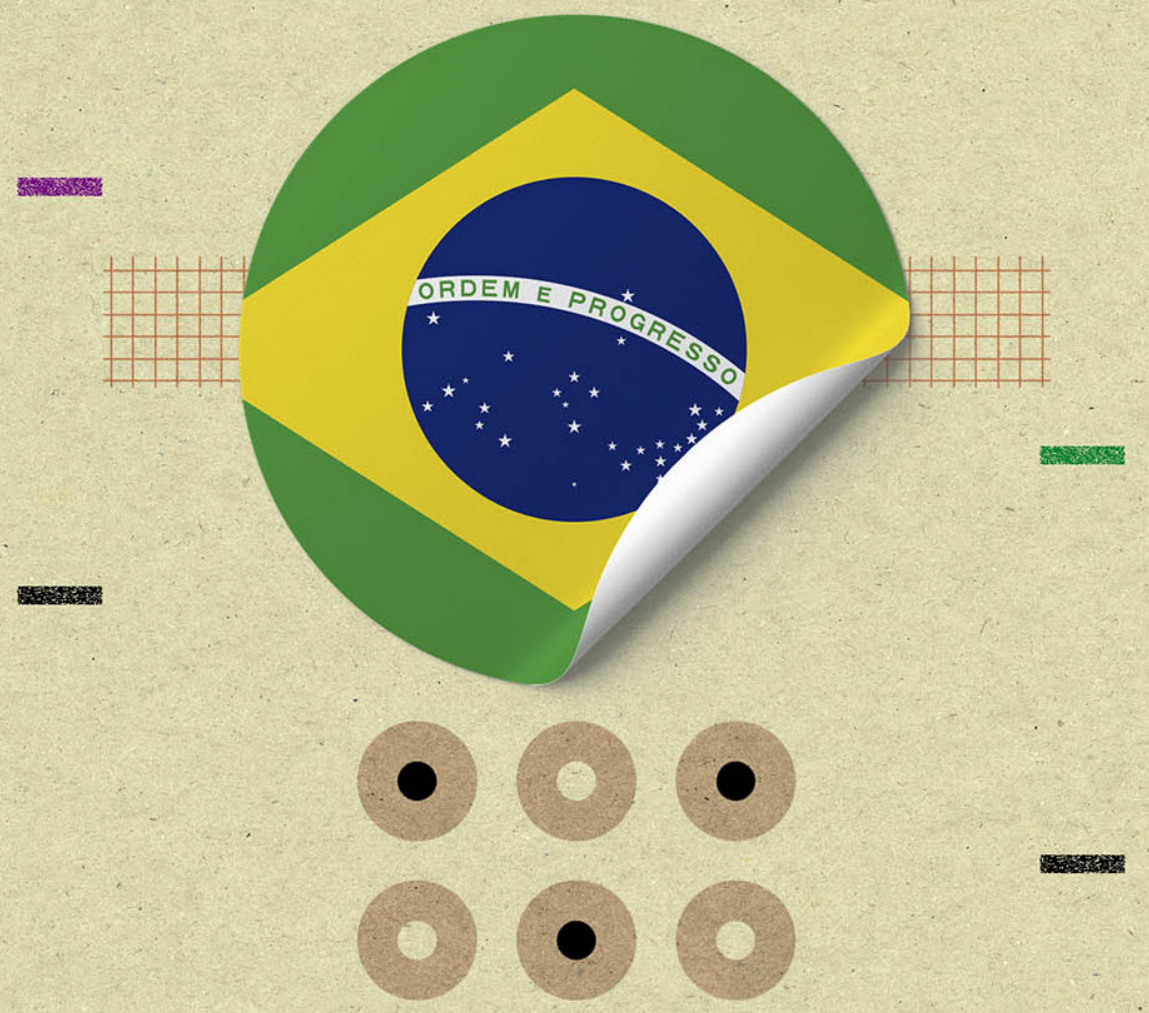




\section{Referências}

ARRETCHE, M. T. DA S. Políticas sociais no Brasil: descentralização em um Estado federativo. Revista Brasileira de Ciências Sociais, v. 14, n. 40, pp. 111-141, 1999.

BARDIN, L. Análise de Conteúdo. Lisboa: Edições 70, 1977. v. 22.

BRASIL. Constituição da República Federativa do Brasil. Brasília: Senado Federal, 1988.

CARVALHO, J. M. Cidadania no Brasil. O longo caminho. 3. ed. Rio de Janeiro: Civilização Brasileira, 2016.

DAGNINO, E.; FERLIM, U. \& ROMANELLI, D. Cultura democrática e cidadania. Opinião Pública, v. 5, n. 1, pp. 20-71, 1998.

ESPING-ANDERSEN, G. O futuro do welfare state na nova ordem mundial. Lua Nova: Revista de Cultura e Política, n. 35, pp. 73-111, 1995.

GRANOVETTER, M. Threshold models of collective behavior. The American Journal of Sociology, v. 83, n. 6, pp. 1420-1443، 1978.

HEIWOOD, A. Political theory: an introducttion. 3. ed. London: Palgrave Macmillan, 2004.

HOWLETT, M. A dialética da opinião pública: efeitos recíprocos da política pública e da opinião pública em sociedades democráticas contemporâneas. Opinião Pública, v. 6, n. 2, pp. 167-186, 2000.

JENKINS-SMITH, H. et al. Belief System Continuity and Change in Policy Advocacy Coalitions: Using Cultural Theory to Specify Belief Systems, Coalitions, and Sources of Change. Policy Studies Journal, v. 42, n. 4, pp. 484-508, 2014.

JENKINS, J. C. Nonprofit Organizations and Policy Advocacy. In: POWELL, W. (Org.). The Nonprofit Sector: A Research Handbook. New Haven: Yale University, pp. 296-318, 1987.

KERSTENETZKY, C. L. Notas sobre as tendências recentes do "welfare state" e possíveis lições para o Brasil. Revista Política Social e desenvolvimento, n. 2, pp. 6-13, 2014.
KINGDON, J. W. Agendas, Alternatives, and Public Policies. 2nd. ed. New York: Harper Collins College, 1995.

KYMLICKA, W. \& NORMAN, W. Return of the Citizen: A Survey of Recent Work on Citizenship Theory. Ethics, v. 104, n. 2, p. 352-381, 1994.

MARSHALL, T. H. Cidadania, classe social e status. tradução Meton P. Gabriela. p. 220, 1967.

OCDE. Relatórios econômicos Brasil 2018. Disponível em: https://bit.ly/3rr6hXM. Acceso em: 15 jun. 2021.

SABATIER, P. A. An advocacy coalition framework of policy change and the role of policy-oriented learning therein. Policy Sciences, v. 21, n. 2-3, pp. 129-168, 1988.

SABATIER, P. A. The advocacy coalition framework: Revisions and relevance for europe. Journal of European Public Policy, v. 5, n. 1, pp. 98-130, 2011.

SECCHI, L. Administração Pública e Gestão Social Formação da Agenda: Método de Policy Advocacy para Ensino de Políticas Públicas. Administração Pública e Gestão Social, v. 4, n. 1, pp. 32-47, 2012.

SPOSATI, A. Social protection and social security in Brazil: agenda for the social worker's work. Serviço Social \& Sociedade, n. 6, pp. 652-674, 2013.

SPOSATI, A. DE O. et al. Assistência na trajetória das políticas sociais brasileiras: uma questão de análise. 7. ed. ed. São Paulo: Cortez, 1998.

SUBIRATS, J. Definición del problema. Relevancia pública y formación de la agenda de actuación de los poderes públicos. In: SARAVIA, E. \& FERRAREZI, E. (Org.). Políticas públicas. Brasília: ENAP Escola Nacional de Administração Pública, 2006. 
WEIBLE, C. M. \& SABATIER, P. A. Theories of the Policy Process. New York: Routledge, 2006.

YAZBEK, M. C. Classes subalternas e assistência social. São Paulo: Cortez, 2016.
YOUNG, I. M. Polity and Group Difference: A Critique of the Ideal of Universal Citizenship. Ethics, v. 99, n. 2, pp. 250-274, 1989.

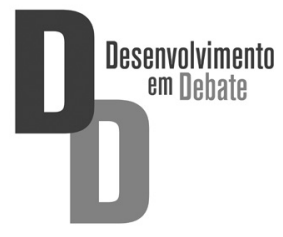

